\title{
SPECTRAL VEGETATION INDEXES APPLIED TO NITROGEN SUFFICIENCY INDEX: A STRATEGY WITH POTENTIAL TO INCREASE NITROGEN USE EFFICIENCY ON TOMATO CROP
}

\author{
Thiago F. Oliveira ${ }^{*}$, Francisco A. C. Pinto², Derly J. H. Silva ${ }^{2}$
} ${ }^{1 *}$ Corresponding author. Universidade Federal de Viçosa/ Viçosa - MG, Brasil. E-mail: thiago.furtado.ufv@gmail.com
ORCID ID: https://orcid.org/0000-0002-5058-7773

\section{KEYWORDS}

fruit quality, precision agriculture, tomato nutrition, variable rate fertilization.

\begin{abstract}
The tomato crop is one of the most demanding of nitrogen fertilizers. This element on soil has an elevated mobility that can represent danger to the environment and reduces its efficiency. Therefore, the purpose of this study was to evaluate the methodology for recommending nitrogen fertilizer for tutored tomatoes with a variable rate based on nitrogen sufficiency index. The treatments consisted of a reference plot and five treatments with the nitrogen sufficiency index calculated on spectral indexes NDVI, GNDVI, MCARI, PSSRa and the SPAD value. The productivity was evaluated considering the fruits size and viability. The descriptors of quality, color, soluble solids, total acidity, titratable acidity and flavor were also evaluated. All the indexes evaluated decreased significantly with the applied nitrogen during the cycle, the only exception being MCARI, which resulted in a similar nitrogen quantity to the reference. The NDVI, GNDVI, PSSRa and SPAD value indexes presented a total applied nitrogen decrease varying from $25.2 \%$ to $43.8 \%$, neither reducing significantly the productivity nor the fruits quality. The marketable fruits productivity varied from 2332.9 to 2773.8 g.plant $^{-1}$ among treatments. Only the NDVI and the SPAD value presented significant improvements on the partial factor of nitrogen productivity, among the applied treatments.
\end{abstract}

\section{INTRODUCTION}

The tomato culture is worldwide and year after year, its production breaks records. In 2016, the world production was 177 million tons, an increase of $132 \%$ compared to the year 1990. Worldwide, the cultivated area has grown $62 \%$ between 1990 and 2016 (FAO, 2017). The more significant increase in production than the increase of cultivated area is due to the better culture productivity, because of genetic improvement and more adequate cultivation techniques.

Among the vegetables crops, tomato is one of the most nitrogen demanding cultures, with recommended doses close to $400 \mathrm{~kg} \cdot \mathrm{ha}^{-1}$ depending on soil type, as for tutored tomato (Ribeiro et al., 1999).

The majority of nitrogen utilized on agriculture has elevated reactivity, making it highly mobile on the biosphere. When there is an excess of nitrate $\left(\mathrm{NO}_{3}\right)$, the nitrogen leach out and/or runoff due to rains or excessive irrigation (Billen et al., 2013) representing a contamination risk for the groundwater reservoirs and streams (AlRawabdeh et al., 2014; Chaudhuri \& Ale, 2014; Huang et al., 2015). Losses may occur in a gaseous form by ammonia $\left(\mathrm{NH}_{3}\right)$ volatilization, nitrogen dioxide $\left(\mathrm{NO}_{2}\right)$ release and reactive oxides $\left(\mathrm{NO}_{\mathrm{X}}\right)$ coming from the nitrification and denitrification processes (Butterbach-Bahl et al., 2013).

Due to its high mobility and the great nutritional demand from cultures, the mineral nitrogen forms are incapable of remaining on soil for long periods of time, meaning that the applied nitrogen does not present a prolonged residual effect (Guilherme et al., 1995). Therefore, the efficient nitrogen use depends on the synchrony between the nutrient supply and the culture need (Tremblay et al., 2011).

For the synchrony between the nutrient supply and the culture need, Francis \& Piekielek (1999) proposed the use of the nitrogen sufficiency index (NSI) to manage the specific fertilization site, comparing measures carried out with the chlorophyll meter - SPAD, between a properly fertilized reference plot and the rest of the crop to be fertilized.

The elevated need of nitrogen for the tomato culture, the low residual effect of this nutrient on soil and the variations on the soil and climate conditions of the crop, indicate that precision agriculture and the nitrogen application on a variable rate have the potential to improve the efficiency use of this fertilizer. Applying a variable rate

\footnotetext{
${ }^{2}$ Universidade Federal de Viçosa/ Viçosa - MG, Brasil.

Received in: 8-8-2018

Accepted in: 12-4-2018
} 
helps the synchrony between the nutrient supply and the culture demand (Arregui \& Quemada, 2008), optimizing the applied nitrogen amount and not decreasing the culture productivity or the fruits quality. In addition to reducing production costs, it reduces the groundwater contamination risk (Billen et al., 2013).

There are several studies aiming to identify the nutritional state of nitrogen in a non- destructive way (Aparicio et al., 2000; Gabriel et al., 2017; Thorp et al., 2017; Hunt et al., 2018), but there is a lack in researches aiming the nitrogen application on a variable rate, especially for tutored tomatoes. Thus, this study has the goal to evaluate the methodology for nitrogen application on a variable rate recommendation for tutored tomatoes based on NSI and its impact on productivity, the fruits quality and the nitrogen partial factor productivity. Beyond the measures carried out with the SPAD, the Normalized Difference Vegetation Index (NDVI), Green Normalized Difference Vegetation Index (GNDVI), Modified Chlorophyll Absorption in Reflectance Index (MCARI) and Pigment Specific Simple Ratio (PSSRa) were used for the NSI calculation.

\section{MATERIAL AND METHODS}

\section{Location and growing conditions}

The experiment was installed on a protected environment, covered with plastic film Suncover AV Blue, $120 \mu \mathrm{m}$ thick, located in Viçosa (latitude $20^{\circ} 45^{\prime} \mathrm{S}$, longitude $42^{\circ} 50^{\prime} \mathrm{W}$ and altitude of $648 \mathrm{~m}$ ), Minas Gerais, Brazil. The tomato plants of the 'Santa Cruz' group, 'Santyno' F1 hybrid were cultivated in 10 liter vases, with a diameter of 30 centimeters, filled with a low fertility soil and textural classification sandy clay loam. The chosen spacing was 30 $\mathrm{cm}$ between plants and one meter between lines.

\section{Fertilization}

Previous to the seedlings transplantation, the soil $\mathrm{pH}$ was corrected, elevating the base saturation to $80 \%$ using dolomitic limestone. The fertilization with NPK carried out in accordance with Ribeiro et al. (1999) for tutored tomatoes based on physicochemical soil analysis.

The fertilizations were carried out weekly using water-soluble fertilizers previously diluted so that the volume of one liter corresponded with the weekly dose of fertilizer for a plant. If the electrical conductivity (EC) surpassed $2.5 \mathrm{dS} . \mathrm{m}^{-1}$, it was diluted until the EC dropped below this value and the weekly fertilization was plotted so that a maximum of liter per day of the solution was applied, avoiding losses by leaching.

The reference plot received an equivalent dose from $300 \mathrm{~kg} \mathrm{ha}^{-1}$ to $\mathrm{N}, 900 \mathrm{~kg} \mathrm{ha}^{-1}$ of $\mathrm{P}_{2} \mathrm{O}_{5}$ and $600 \mathrm{~kg} \mathrm{ha}^{-1}$ of $\mathrm{K}_{2} \mathrm{O}$. Such dose was plotted weekly over 18 weeks, based on what Alvarenga (2004) proposed. The plants also received equivalent doses from $4 \mathrm{~kg} \mathrm{ha}^{-1}$ of $\mathrm{B}$ and $2 \mathrm{~kg} \mathrm{ha}^{-1}$ of $\mathrm{Zn}$ over 7 weeks, from the $7^{\text {th }}$ to the $14^{\text {th }}$ week after the transplants and $20 \mathrm{~kg} \mathrm{ha}^{-1}$ of $\mathrm{Mg}$ over 14 weeks, from the $2^{\text {nd }}$ to the $16^{\text {th }}$ week after the transplants.

TABLE 1. Nutrients distribution over the tomato cycle utilized for the reference plot.

\begin{tabular}{|c|c|c|c|c|c|c|}
\hline \multirow{2}{*}{$\begin{array}{c}\text { Days after } \\
\text { transplanting }\end{array}$} & $\mathbf{N}$ & $\mathbf{P}_{2} \mathbf{O}_{5}$ & $\mathrm{~K}_{2} \mathrm{O}$ & Mg & B & Zn \\
\hline & \multicolumn{6}{|c|}{ 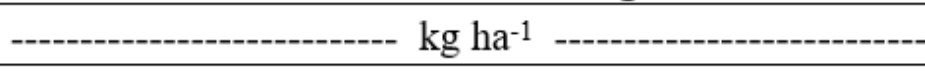 } \\
\hline 0 & 0 & 78.3 & 0 & & & \\
\hline 7 & 0.9 & 2.7 & 1,8 & $\uparrow$ & & \\
\hline 14 & 0.9 & 2.7 & 1,8 & & & \\
\hline 21 & 0.9 & 2.7 & 1,8 & & & \\
\hline 28 & 1.5 & 4.5 & 3 & & & \\
\hline 35 & 2.4 & 10.8 & 4.8 & & & \\
\hline 42 & 3.9 & 11.7 & 7.8 & & $\Delta$ & $\Delta$ \\
\hline 49 & 37.2 & 103.5 & 74.4 & 1 & & \\
\hline 56 & 37.2 & 103.5 & 74.4 & 20.0 & & \\
\hline 63 & 37.2 & 103.5 & 74.4 & & 40 & 20 \\
\hline 70 & 37.2 & 82.8 & 74.4 & & 4.0 & 2.0 \\
\hline 77 & 37.2 & 62.1 & 74.4 & & & \\
\hline 84 & 29.7 & 62.1 & 59.4 & & & \\
\hline 91 & 22.2 & 62.1 & 44.4 & & $\nabla$ & $\nabla$ \\
\hline 98 & 18.6 & 62.1 & 37.2 & & & \\
\hline 105 & 18.6 & 62.1 & 37.2 & $\downarrow$ & & \\
\hline 112 & 14.7 & 62.1 & 29.4 & & & \\
\hline 119 & 0 & 20.7 & 0 & & & \\
\hline 126 & 0 & 0 & 0 & & & \\
\hline
\end{tabular}

$\mathrm{N}$ - nitrogen; $\mathrm{P}_{2} \mathrm{O}_{5}$ - phosphorus pentoxide; $\mathrm{K}_{2} \mathrm{O}$ - potassium oxide; $\mathrm{Mg}$ - magnesium; $\mathrm{B}$ - boron; $\mathrm{Zn}$ - zinc. 


\section{Trial design and data analysis}

The experiment used randomized blocks, with six treatments and six repetitions. Each plot was composed of six vases, with those at the extremities considered as boards, unevaluated during the experiment.

The normality was tested using Lilliefors' test and the variances equality checked by the Bartlett's test. The statistics analysis carried out through the ANOVA and Tukey's test at $5 \%$ of probability for average comparisons.

\section{Treatments}

For the treatments, the fertilization was carried out utilizing the same amount and temporal distribution of fertilizers as the reference plot, except for the nitrogen, which was applied only when the calculated NSI average for that treatment was equal or less than 0.95 .

\section{Obtainment of spectral readings and SPAD value}

The readings were carried out during the period between 7:00 a.m. to $12: 00$, on the $29^{\text {th }}, 36^{\text {th }}, 44^{\text {th }}, 50^{\text {th }}, 69^{\text {th }}$, $77^{\text {th }}, 97^{\text {th }}, 105^{\text {th }}$ days after transplanting (DAT), utilizing the $4^{\text {th }}$ leaf, from the apex, completely expanded.

For the spectral readings, the ASD FieldSpec ${ }^{\circledR}$ HandHeld $2^{\mathrm{TM}}$ spectral radiometer was utilized. It is capable of carrying out reflectance readings from 325 to $1075 \mathrm{~nm}$. The equipment calibration was carried out before the beginning of readings and in each 30-minute period of use. For the calibration a Spectralon ${ }^{\circledR}$ SRS-99 disc was utilized. Two readings of each leaf in each of 24 plants, in a total of 48 readings by treatment were realized.

The SPAD values were obtained with the Minolta SPAD-502 chlorophyll meter. On each leaf in each of 24 plants, six readings were carried out, with a total of 144 readings by treatment.

\section{Spectral indexes and NSI calculation}

The indexes equations utilized for the NSI calculation are on Table 2 .

TABLE 2. Spectral indexes utilized and their equations.

\begin{tabular}{ccc}
\hline Index & Equation & \\
\hline NDVI & $\frac{\rho_{800}-\rho_{670}}{\rho_{800}+\rho_{670}}$ & (Daughtry, 2000) \\
GNDVI & $\frac{\rho_{801}-\rho_{550}}{\rho_{801}+\rho_{550}}$ & $(1)$ \\
MCARI & {$\left[\left(\rho_{700}-\rho_{670}\right)-0.2 \times\left(\rho_{700}-\rho_{550}\right)\right] \times\left(\frac{\rho_{700}}{\rho_{670}}\right)$} & $($ Daughtry, 2000) \\
PSSR $_{\mathrm{a}}$ & $\frac{\rho_{800}}{\rho_{680}}$ & (Dlaughtry, 2000) \\
\hline
\end{tabular}

$\rho 550$ - reflectance on the 550nm wavelength; $\rho 670$ - reflectance on the $670 \mathrm{~nm}$ wavelength; $\rho 700$ - reflectance on the $700 \mathrm{~nm}$ wavelength; $\rho 800$ - reflectance on the $800 \mathrm{~nm}$ wavelength; $\rho 801$ - reflectance on the $801 \mathrm{~nm}$ wavelength.

The NSI calculation was realized according to the [eq. (5)] for all the indexes except for the MCARI, which possessed the inverse relation to the foliar nitrogen concentration (Daughtry, 2000). For that index the inverse [eq. (5)] was used.

$$
N S I=\frac{\text { Index value on treatment }}{\text { Index value on reference plot }}
$$

\section{Productivity}

To evaluate the productivity, it was utilized the fruits weight per plant. The production of large, medium, small, total, marketable and defective fruits were evaluated (Table 3). It was considered as defective fruits those ones that showed apex rot, deformation, open or cracked fruits and fruits with less than a $40 \mathrm{~mm}$ diameter.

TABLE 3. Size classification of oblong tomato fruits.

\begin{tabular}{cc}
\hline Class & $\begin{array}{c}\text { (MTD) } \\
(\mathrm{mm})\end{array}$ \\
\hline Defective & Less than 40 \\
Small & More than 40 until 50 \\
Medium & More than 50 until 60 \\
Large & More than 60 \\
\hline
\end{tabular}

MTD - Most transversal diameter.

SOURCE: MAPA, 2002 modified.

\section{Fruits Quality}

Three totally mature fruits from each plot were collected and taken to the laboratory for color analysis, soluble solids (SS), total acidity ( $\mathrm{pH})$, titratable acidity (TA) and flavor. The color obtained in two opposite spots on the equatorial region of each fruit, utilizing a CR-10 Minolta portable colorimeter, with the CIELab color coordinates system.

After the color obtainment, the fruits were crushed, and their pulp homogenized. The soluble solids were quantified with the undiluted pulp on the digital Hanna HI96801 refractometer and the result was expressed in ${ }^{\circ}$ Brix.

The total acidity was obtained with the undiluted pulp by inserting the probe of the Digimed DM-22 bench pH meter which was previously calibrated. The titratable acidity was obtained with a five-gram sample of diluted pulp in volumetric flask; to complete $100 \mathrm{~mL}$ of this solution, $10 \mathrm{~mL}$ was pipetted and titrated with $\mathrm{NaOH} 0.1$ mol.L $L^{-1}$. Two repetitions for each sample was carried out and expressed in citric acid percentage. 
The flavor was obtained by the relation between soluble solids and titratable acidity, according to [eq. (6)] (Kader et al., 1978).

$$
\text { Flavor }=\frac{S S}{T A}
$$

Where,

SS - soluble solids, in ${ }^{\circ}$ Brix,

TA - titratable acidity, in citric acid percentage.

\section{Partial factor productivity of nitrogen $\left(\mathrm{PFP}_{\mathrm{N}}\right)$}

The Partial factor productivity of nitrogen was calculated, according to the equation proposed by Fixen et al., (2015), dividing the total fruits production by the applied nitrogen dose on fertilizations [eq.(7)].

$$
P F P_{N}=\frac{Y}{N}
$$

Where,

PFPN - Partial factor productivity of nitrogen in

$\mathrm{kg}_{\text {fruits }} \mathrm{kg}_{\text {nitrogen }}{ }^{-1}$;

$\mathrm{Y}$ - Total fruits production in $\mathrm{kg}$,

$\mathrm{N}$ - Applied nitrogen dose in $\mathrm{kg}$.

\section{RESULTS AND DISCUSSION}

During the experiment period, climatic variables were monitored by an observation station of automatic surface from the National Institute of Meteorology INMET (Station of Viçosa - A510).

The higher daylight (day period with solar radiation) and nocturnal average temperatures observed were respectively 28 and $21.7^{\circ} \mathrm{C}$, and the lower from 15.5 and $9.9{ }^{\circ} \mathrm{C}$. The daily solar radiation varied from 2.1 to 24.5 $\mathrm{MJ} . \mathrm{m}^{2}$.day ${ }^{-1}$ with an average of $14.0 \mathrm{MJ} . \mathrm{m}^{2}$.day ${ }^{-1}$ (figure 1).
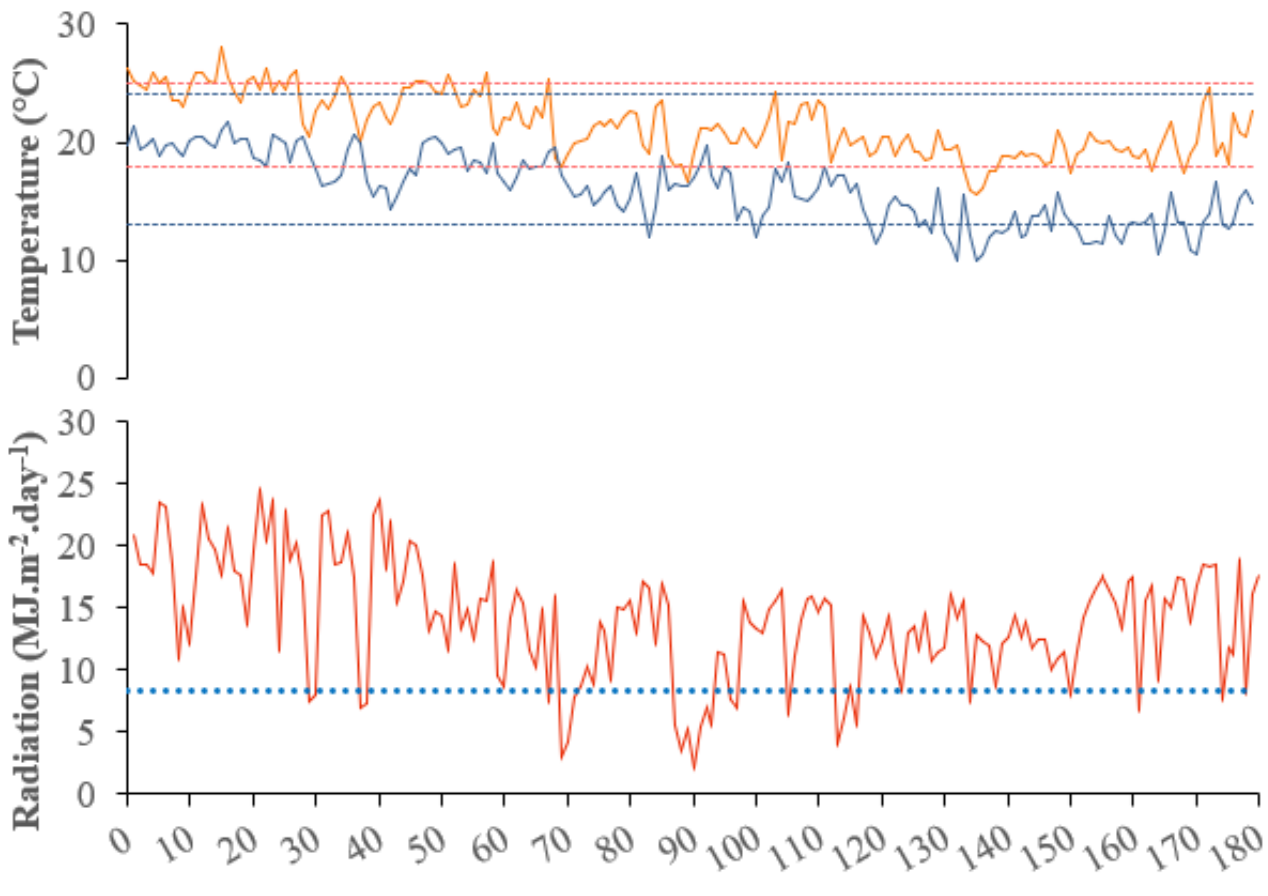

DAT (Days After Transplanting)

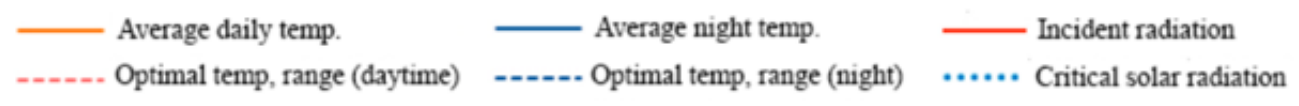

FIGURE 1. Daylight, nocturnal and ideal gap average temperatures for tomatoes (Dusi et al., 1993); daily solar radiation and critic level for tomatoes (Schmidt et al., 2017).

\section{NSI, spectral indexes and SPAD values}

The spectral indexes, SPAD values and NSI obtained within the crop cycle are on figure 2, as well as fertilizations realized during the observations period.

The spectral indexes NDVI, GNDVI, PSSRa and the SPAD values presented a similar behavior during the observations period, with lower values observed between the $29^{\text {th }}$ and the $50^{\text {th }}$ DAT, period that a smaller fertilizer quantity was applied weekly compared to the rest of the cycle. The comprehended period between the $50^{\text {th }}$ and the $71^{\text {st }}$ DAT characterized by a gradual decline on incident solar radiation, attained values below the trophic limit for tomatoes, considering $8.4 \mathrm{MJ} \cdot \mathrm{m}^{2}$.day ${ }^{-1}$. In this radiation threshold the energy expended with respiration equals the energy produced through photosynthesis (Andriolo, 2000) concomitant with the period when it was not possible to obtain the spectral indexes due to operational problems with the equipment, this way all the treatments received nitrogen in fertilizations, resulting in an elevation in NDVI, GNDVI, PSSRa indexes and SPAD values but a drop in MCARI. With the incident solar radiation directly related to the nitrogen absorption capacity (Peng \& Cassman, 1998), the supplied nitrogen in this period was not a bounding factor that approached the SPAD values and spectral indexes of the treatments with those of the reference plot, elevating the 
NSI to values close to one in all treatments, exception made by $\mathrm{T}_{\text {MCARI. }}$. These results indicate the sensibility of the variable rate nitrogen fertilization based on NSI method to local soil and climatic conditions.

The NSI values observed on $\mathrm{T}_{\mathrm{GNDVI}}$ and $\mathrm{T}_{\mathrm{PSSR}}$ treatments were similar in behavior over the time, with gradual decline between the $29^{\text {th }}$ and the $50^{\text {th }}$ DAT, going below the 0.95 threshold on the $50^{\text {th }}$ DAT, increasing above it on the $69^{\text {th }}$ and the $78^{\text {th }}$ DAT, below the threshold again from the $97^{\text {th }}$ and the $105^{\text {th }}$ DAT.
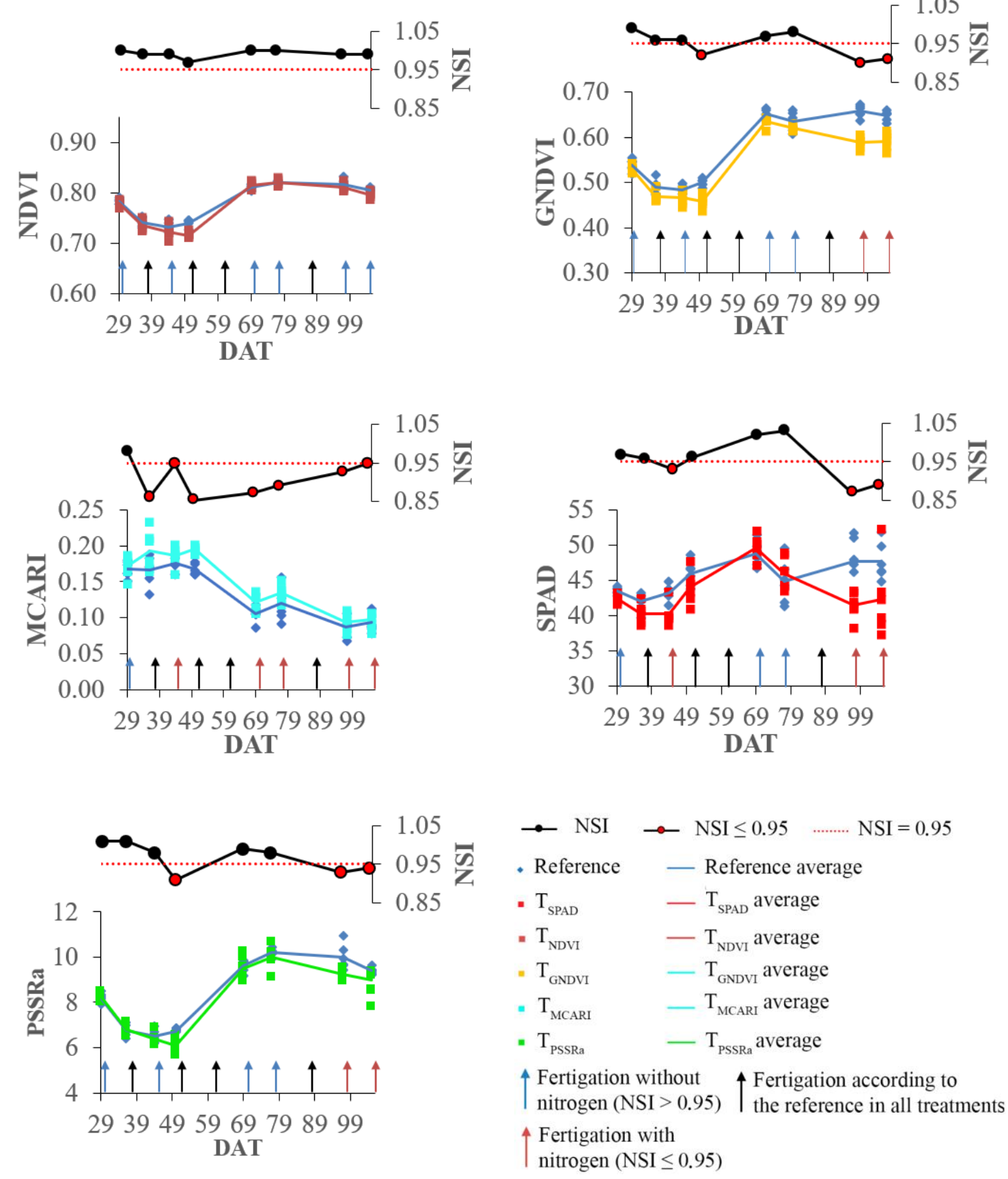

FIGURE 2. SPAD Values and spectral indexes on the reference plot compared with the other treatments, calculated NSI during the periods and form as the fertilizations were realized during the observation period.

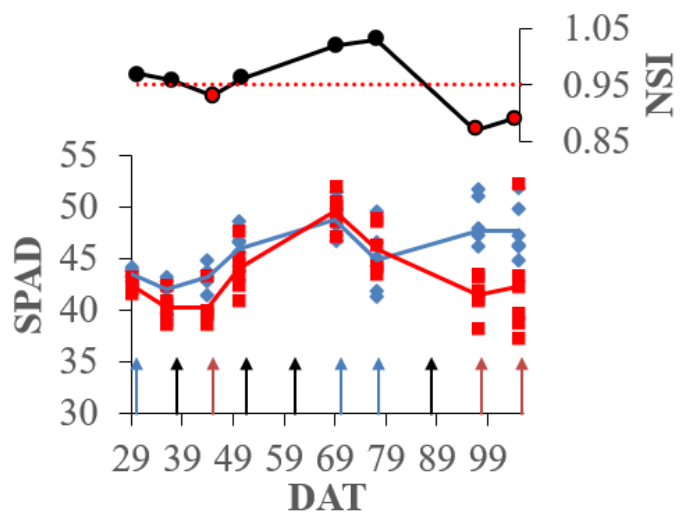
value below the $\mathrm{T}_{\text {GNDVI }}$ and $\mathrm{T}_{\text {PSSRa }}$ treatments, but presented a above 0.95 during the entire observed period, reflex of the low difference between the index's values observed on the reference parcel and the $\mathrm{T}_{\mathrm{NDVI}}$ treatment.

The $\mathrm{T}_{\text {MCARI }}$ treatment only presented an NSI value above the limit on the $29^{\text {th }}$ DAT, with gradual elevation between the $50^{\text {th }}$ and the $105^{\text {th }}$ DAT.

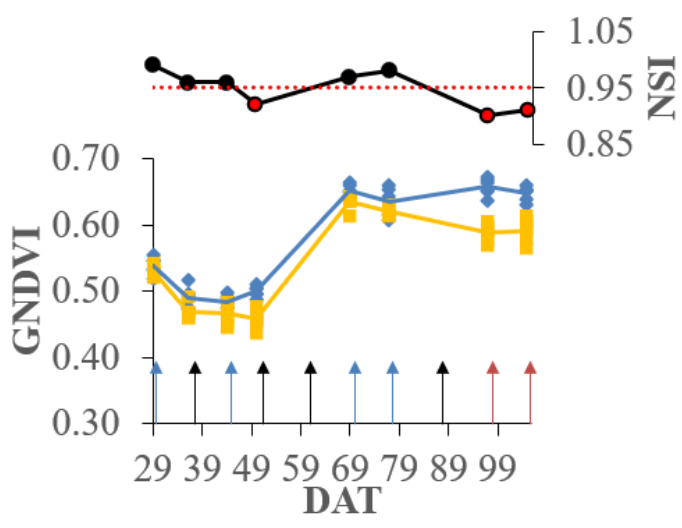

DAT
The calculated NSI for the $\mathrm{T}_{\mathrm{NDVI}}$ treatment remained 
On the $37^{\text {th }}, 52^{\text {nd }}, 61^{\text {st }}$ and the $88^{\text {th }}$ DAT it was not possible to obtain the spectral readings, thus there was no difference on the nitrogen fertilization among the treatments (black arrows on figure 2). Every treatment was fertilized according to the reference on these periods.

\section{Nitrogenous fertilization}

The applied nitrogen total dose for treatments and the reference plot are on figure 3.

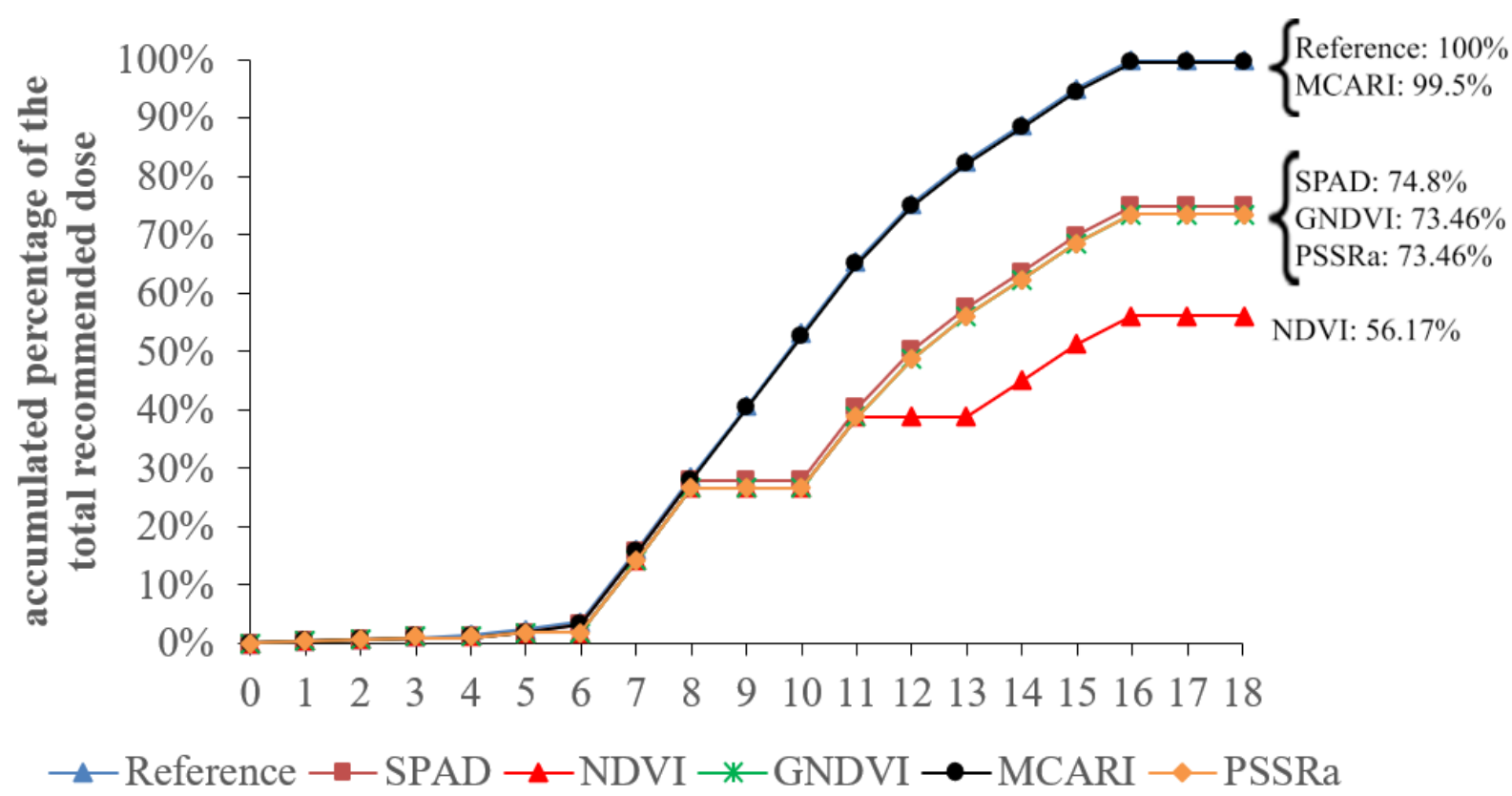

FIGURE 3. Total accumulated nitrogen applied over the culture cycle for each treatment and for the reference plot.

The $\mathrm{T}_{\mathrm{SPAD}}, \mathrm{T}_{\mathrm{NDVI}}, \mathrm{T}_{\mathrm{GNDVI}}$ and $\mathrm{T}_{\mathrm{PSSRa}}$ treatments lead to a total applied nitrogen reduction between $25.2 \%$ and $43.8 \%$ of the total recommended dose. The $\mathrm{T}_{\text {MCARI }}$ treatment presenting NSI values below 0.95 during almost all the observed period resulted in a similar nitrogen reference dose.

\section{Productivity}

There was a significant statistical difference of a 5\% probability level on productivity average for medium size fruits and defective fruits. On the other evaluated productivity indicators, statistical differences among averages have not been detected (Table 4).

TABLE 4. p-value and productivity average of treatments and reference plot in fruit size, presence of defects, marketable and total fruits productivity.

\begin{tabular}{lcccccc}
\hline & LFP & MFP* & SFP & MFP & DFP* & TP \\
\cline { 2 - 7 } Treatment & \multicolumn{7}{c}{ p-value } \\
\cline { 2 - 7 } & 0.813 & 0.006 & 0.282 & 0.091 & 0.012 \\
\hline & \multicolumn{7}{c}{ Productivity } \\
\cline { 2 - 7 } Reference & 1452.08 & $1119.35 \mathrm{a}$ & 131.71 & 2773.80 & $93.18 \mathrm{ab}$ & 2866.98 \\
TSPAD & 1505.53 & $1015.85 \mathrm{ab}$ & 145.23 & 2738.90 & $50.22 \mathrm{~b}$ & 2789.12 \\
T $_{\text {NDVI }}$ & 1508.95 & $866.89 \mathrm{ab}$ & 113.99 & 2577.80 & $112.45 \mathrm{a}$ & 2690.25 \\
T $_{\text {GNDVI }}$ & 1303.80 & $788.38 \mathrm{~b}$ & 168.13 & 2332.90 & $127.49 \mathrm{a}$ & 2460.39 \\
TMCARI & 1545.31 & $1018.56 \mathrm{ab}$ & 108.71 & 2752.62 & $98.18 \mathrm{ab}$ & 2850.80 \\
TPSSRa & 1354.15 & $907.00 \mathrm{ab}$ & 139.10 & 2478.68 & $111.64 \mathrm{a}$ & 2590.32 \\
\hline
\end{tabular}

LFP large fruits productivity; MFP medium fruits productivity; SFP small fruits productivity; TFP marketable fruits productivity; DFP defective fruits productivity; TP total productivity; *averages with the same letter does not differ at $5 \%$ of probability on the Tukey test.

\section{Fruit quality}

There was no significant statistical difference in any of the fruits quality describers evaluated. The describers' averages per treatment and the p-values are on Table 5. 
TABLE 5. p-value averages from fruit quality describers: luminosity (L), red/green coordinated (a), yellow/blue coordinated (b), total acidity $(\mathrm{pH})$, soluble solids in ${ }^{\circ}$ Brix (SS), titratable acidity in citric acid percentage (TA) and Flavor (SS/AT).

\begin{tabular}{|c|c|c|c|c|c|c|c|}
\hline \multirow{4}{*}{ Treatment } & $\mathbf{L}$ & $\mathbf{a}$ & $\mathbf{b}$ & pH & SS & TA & Flavor \\
\hline & \multicolumn{7}{|c|}{ p-value } \\
\hline & 0.817 & 0.121 & 0.951 & 0.860 & 0.233 & 0.187 & 0.821 \\
\hline & \multicolumn{7}{|c|}{ Averages } \\
\hline Reference & 37.06 & 18.39 & 22.79 & 4.13 & 4.47 & 0.31 & 13.77 \\
\hline $\mathbf{T}_{\text {SPAD }}$ & 37.61 & 15.60 & 22.18 & 4.15 & 4.13 & 0.30 & 13.92 \\
\hline $\mathbf{T}_{\text {NDVI }}$ & 37.37 & 16.03 & 21.51 & 4.10 & 4.10 & 0.29 & 14.20 \\
\hline T $_{\text {GNDVI }}$ & 37.32 & 17.11 & 21.88 & 4.10 & 3.98 & 0.33 & 12.80 \\
\hline TMCARI $_{\text {MCA }}$ & 37.64 & 15.37 & 21.94 & 4.11 & 4.32 & 0.34 & 12.99 \\
\hline TPSSRa & 37.51 & 17.50 & 22.28 & 4.12 & 3.93 & 0.30 & 13.24 \\
\hline
\end{tabular}

\section{Partial factor productivity of nitrogen averages $\left(\mathbf{P F P}_{\mathrm{N}}\right)$}

The partial factor productivity of nitrogen averages presented significant statistical differences between treatments (Table 6).

TABLE 6. Partial factor of nitrogen productivity averages for the treatments and reference plot.

\begin{tabular}{|c|c|}
\hline Treatment & $\mathbf{P F P}_{\mathbf{N}}\left(\mathrm{kg} \cdot \mathrm{kg}^{-1}\right)$ \\
\hline$\overline{\text { TMCARI }_{\text {MC }}}$ & $318.36 \quad \mathrm{a}$ \\
\hline Reference & $318.56 \quad \mathrm{a}$ \\
\hline T $_{\text {GNDVI }}$ & $372.13 \mathrm{ab}$ \\
\hline TPSSRa & $391.78 \quad a b$ \\
\hline $\mathbf{T}_{\text {SPAD }}$ & $414.33 \mathrm{~b}$ \\
\hline $\mathbf{T}_{\text {NDVI }}$ & $532.13 \mathrm{c}$ \\
\hline
\end{tabular}

Averages with the same letter don't differ at $5 \%$ of probability on Tukey's test;

PFPN - partial factor productivity of nitrogen.

The maximum observed SPAD values in this study are within the threshold observed to study different substrates for tomatoes in a protected environment as described by (Qian et al., 2014), also within values for industrial tomatoes in the fall/spring cycle as Ferreira et al. (2006) described and close to the values for tomatoes of indeterminate growth in ideal nitrogen supply conditions observed by Padilla et al. (2015). The maximum NDVI and GNDVI indexes values observed corroborated with values obtained by Padilla et al. (2015) for tomatoes in ideal nitrogen supply conditions.

The $\mathrm{T}_{\mathrm{SPAD}}, \mathrm{T}_{\mathrm{NDVI}}, \mathrm{T}_{\mathrm{GNDVI}}$ and $\mathrm{T}_{\mathrm{PSSRa}}$ treatments did not receive nitrogenous fertilization on the $70^{\text {th }}$ and the $78^{\text {th }}$ DAT (period that the solar radiation incident increased), they presented spectral indexes and the SPAD values reduction on treatments compared to the reference plot, implicating a decline on NSI values below the 0.95 threshold on the $97^{\text {th }}$ and the $105^{\text {th }}$ DAT except $\mathrm{T}_{\mathrm{NDVI}}$.

The NSI on $\mathrm{T}_{\text {MCARI }}$ treatment presented a value above the 0.95 threshold only on the $29^{\text {th }}$ DAT, followed by a decrease. This could be associated with the fertilization without nitrogen realized on the $30^{\text {th }}$ DAT, however similar behavioral decrease on the $50^{\text {th }}$ DAT was observed also when the treatment received an identical nitrogen dose to the reference plot on the $37^{\text {th }}$ and the $45^{\text {th }}$ DAT. The NSI on $\mathrm{T}_{\text {MCARI }}$ treatment presented a value above the 0.95 threshold on the $29^{\text {th }}$ DAT, followed by a decrease on the $36^{\text {th }}$ DAT.

Despite the $\mathrm{T}_{\mathrm{GNDVI}}$ treatment presenting a significant statistical difference between the average fruits productivity comparing to the reference, such fact does not relate to the applied nitrogen doses, once the $\mathrm{T}_{\mathrm{PSSR}}$ treatment presented nitrogen quantity and temporal distribution identical to the $\mathrm{T}_{\mathrm{GNDVI}}$ treatment, with a medium fruit's productivity statistically as the reference plot.

Diverse effects related to the fruits size were reported for different nitrogen doses, as the non-altered fruits size for nitrogen doses between zero and $600 \mathrm{~kg} \cdot \mathrm{ha}^{-1}$ (Warner et al., 2004) and between zero and $300 \mathrm{~kg} \cdot \mathrm{ha}^{-1}$ (Farneselli et al., 2015) or even for nitrogen doses 25\% and $50 \%$ above the recommendation (Mahajan \& Singh, 2006). Yet Parisi et al. (2006), varying $\mathrm{N}$ doses from zero to 250 $\mathrm{kg} . \mathrm{ha}^{-1}$ reported a variation in fruits size homogeneity, regardless of the applied nitrogen doses.

The difference between the defective fruits productivity among treatments also do not appear to be related with the fertilizer doses and temporal distribution, hence the $\mathrm{T}_{\mathrm{SPAD}}$ treatment that presented the lowest defective fruits productivity received nitrogen in quantity and temporal distribution as the $\mathrm{T}_{\mathrm{GNDVI}}$ and $\mathrm{T}_{\mathrm{PSSRa}}$ treatments, which presented the most defective fruits productivity. In fact, the study with varying doses from zero to $250 \mathrm{~kg} \cdot \mathrm{ha}^{-1}$, Parisi et al. (2006) observed a variation of biotic defects independently of the applied nitrogen doses, there was no significant alteration related to the fruits abiotic defects.

The observed values on the $a$ color coordinate varied from 15.17 to 18.39 being higher than the observed (Radzevičius et al., 2014) in a study of the fruits quality during different ripening stages.

Despite soluble solids increased in a direct manner with increase nitrogen doses applied (Warner et al., 2004; Cayuela et al., 2014; Frias-Moreno et al., 2014; OchoaVelasco et al., 2016), none of the treatments presented a statistically significant difference in ${ }^{\circ}$ Brix compared to the reference or among treatments, indicating that the use of NSI for management of the variable rate fertilization was capable of reducing the applied nitrogen quantity without compromising the fruits soluble solids percentage.

The SS/TA rate is directly related to the fruits flavor. The higher the sugar amount and lower the acidity, the more palatable the fruit will be (Jones, 2007). The observed values of the study are characteristic from high quality fruits, presenting SS/TA>10 for Kader et al. (1978) and

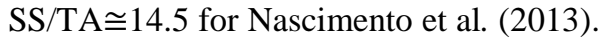

The $\mathrm{T}_{\text {MCARI }}$ treatment and the reference plot presented low $\mathrm{PFP}_{\mathrm{N}}$, result of the higher nitrogen quantity used without significant productivity gain. 
The $\mathrm{T}_{\mathrm{SPAD}}$ and $\mathrm{T}_{\mathrm{NDVI}}$ treatments lead to higher values of $\mathrm{PFP}_{\mathrm{N}}$ than the reference plot, indicating that those treatments had better efficiency on nitrogen utilized compared to the reference plot.

Therefore, this study reinforced the potential of the precision agriculture on the tomato culture. The synchrony between nitrogen supply and the culture demand for a determined soil and climatic condition provoked by the variable application rate, was capable of reducing the applied nitrogen amount, increasing its use efficiency that may also reflect on less water streams contamination risk, leading to the more adequate management of this fertilizer.

\section{CONCLUSIONS}

The utilized methodology lead to reduction of applied nitrogen on $\mathrm{T}_{\mathrm{SPAD}}, \mathrm{T}_{\mathrm{NDVI}}, \mathrm{T}_{\mathrm{GNDVI}}$ and $\mathrm{T}_{\mathrm{PSSR}}$ treatments with no loss of total and marketable fruits productivity or alteration on the fruit's quality.

The utilized methodology was responsive to climatic and soil conditions of the crop, being capable of reducing the applied nitrogen amount between 25.2 and $43.8 \%$ if compared with the recommended dose, and the nitrogen did not become a limiting factor for the culture.

The treatments that used the spectral NDVI index and the SPAD value were capable of improving the nitrogen efficiency utilization by plants.

\section{ACKNOWLEDGEMENTS}

This research was supported by the Federal University of Viçosa and the National Council of Scientific and Technological Development CNPq. We would like to thank our colleague Fábio Delazari for the support with the implementation and conduction of the experiment and to the technician Jamilton Lopes for the help in the analyzes of fruits quality.

\section{REFERENCES}

Alvarenga MA (2004) Tomate: produção em campo, em casa-de-vegetação e em hidroponia. [S.1.]: UFLA

Al-Rawabdeh AM, Al-Ansari N, Al-Taani A, Al-Khateeb F, Knutsson S (2014) Modeling the Risk of Groundwater Contamination using Modified DRASTIC and GIS in Amman-Zerqa Basin, Jordan. Central European Journal Engineering 4(3):264-280. DOI: http://dx.doi.org/10.2478/s13531-013-0163-0

Andriolo JL (2000) Fisiologia da producao de hortalicas em ambiente protegido. Horticultura Brasileira 18:26-33.

Aparicio N, Villegasa D, Casadesusb J, Arausc JL, Royo C (2000) Spectral Vegetation Indices as Nondestructive Tools for Determining Durum Wheat Yield. Agronomy Journal. American Society of Agronomy 92(1):83. DOI: http://dx.doi.org/10.2134/agronj2000.92183x

Arregui LM, Quemada M (2008) Strategies to Improve Nitrogen Use Efficiency in Winter Cereal Crops under Rainfed Conditions. Agronomy Journal 100(2):277-284. DOI: http://dx.doi.org/10.2134/agronj2007.0187
Billen G, Garnier J, Lassaletta L (2013) The nitrogen cascade from agricultural soils to the sea: Modelling nitrogen transfers at regional watershed and global scales. Philosophical Transactions of the Royal Society B: Biological Sciences 368(1621). DOI: http://dx.doi.org/10.1098/rstb.2013.0123

Blackburn GA (1998) Quantifying Chlorophylls and Caroteniods at Leaf and Canopy Scales Remote Sensing of Environment 66(3):273-285. DOI:

http://dx.doi.org/10.1016/S0034-4257(98)00059-5

Butterbach-Bahl K, Baggs EM, Dannenmann M, Kiese R, Zechmeister-Boltenstern S (2013) Nitrous oxide emissions from soils: how well do we understand the processes and their controls? Philosophical Transactions of the Royal Society B: Biological Sciences 368(1621):2013012220130122. DOI: http://dx.doi.org/10.1098/rstb.2013.0122

Cayuela ML, van Zwieten L, Singh BP, Jeffery S, Roig A, Sánchez-Monedero MA (2014) Biochar's role in mitigating soil nitrous oxide emissions: A review and meta-analysis. Agriculture, Ecosystems and Environment 191:5-16. DOI:

http://dx.doi.org/10.1016/j.agee.2013.10.009

Chaudhuri S, Ale S (2014) Long term (1960-2010) trends in groundwater contamination and salinization in the Ogallala aquifer in Texas. Journal of Hydrology 513:376390. DOI:

http://dx.doi.org/10.1016/J.JHYDROL.2014.03.033

Daughtry C (2000) Estimating Corn Leaf Chlorophyll Concentration from Leaf and Canopy Reflectance. Remote Sensing of Environment 74(2):229-239. DOI: http://dx.doi.org/10.1016/S0034-4257(00)00113-9

Dusi AN, Lopes CA, Oliveira CAS, Moreira HM, Miranda JEC de, Charchar JM, Silva JLO, Magalhães JR, Branco MC, Reli NVB, Maklshlma N, Fontes RR, Pereira W, Horlno Y (1993) A cultura do tomateiro (para mesa). EMBRAPA-SPI. Coleção plantar.

FAO (2017) FAOSTATS. Available in: http://www.fao.org/faostat/en/\#data.

Farneselli M, Benincasa P, Tosti G, Simonne E, Guiducci M, Tei F (2015) High fertigation frequency improves nitrogen uptake and crop performance in processing tomato grown with high nitrogen and water supply. Agricultural Water Management 154:52-58. DOI: http://dx.doi.org/10.1016/j.agwat.2015.03.002

Ferreira MMM, Ferreira GB, Fontes PCR, Dantas JP (2006) Índice spad e teor de clorofila no limbo foliar do tomateiro em função de doses de nitrogênio e da adubação orgânica, em duas épocas de cultivo. Revista Ceres 53(305):83-92. Available in:

http://www.redalyc.org/resumen.oa?id=305226787012\%5 Cnhttp://www.redalyc.org/pdf/3052/305226787012.pdf.

Fixen P, Brentrup F, Bruulsema TW, Garcia F, Norton R, Zingore S (2015) Nutrient/fertilizer use efficiency: Measurement, current situation and trends. Managing Water and Fertilizer for Sustainable Agricultural Intensification, p 270. 
Francis D, Piekielek W (1999) Assessing crop nitrogen needs with chlorophyll meters. Site-Specific Management Guidelines, Potash and Phosphate Institute (605).

Available in:

http://scholar.google.com/scholar?hl=en\&btnG=Search\&q =intitle:Assessing+Crop+Nitrogen+Needs+with+Chloroph yll+Meters\#0.

Frias-Moreno N, Nuñez-Barrios A, Perez-Leal R, Gonzalez-Franco AC, Hernandez-Rodriguez A, RoblesHernandez L (2014) Effect of nitrogen deficiency and toxicity in two varieties of tomatoes (Lycopersicum esculentum L.). Agricultural Sciences 5(14):136-1368. DOI: http://dx.doi.org/10.4236/as.2014.514146

Gabriel JL, Zarco-Tejada RJ, López-Herrera PJ, PérezMartín E, Alonso-Ayuso M, Quemada M (2017) Airborne and ground level sensors for monitoring nitrogen status in a maize crop. Biosystems Engineering 160:124-133. DOI: http://dx.doi.org/10.1016/j.biosystemseng.2017.06.003

Guilherme LRG, Vale FR, Guedes GAA (1995)

Fertilidade do solo: dinâmica e disponibilidade dos nutrientes de plantas. Lavras, UFLA.

Huang G, Huang Y, Hu H, Liu F, Zhang Y, Deng R (2015) Remediation of nitrate-nitrogen contaminated groundwater using a pilot-scale two-layer heterotrophicautotrophic denitrification permeable reactive barrier with spongy iron/pine bark. Chemosphere 130:8-16. DOI: http://dx.doi.org/10.1016/J.CHEMOSPHERE.2015.02.029

Hunt ER, Horneck DA, Spinelli CB, Turner RW, Bruce AE, Gadler DJ, Brungardt JJ, Hamm PB (2018) Monitoring nitrogen status of potatoes using small unmanned aerial vehicles. Precision Agriculture 19(2):314-333. DOI: http://dx.doi.org/10.1007/s11119-017-9518-5

Jones JB (2007) Tomato plant culture: in the field, greenhouse, and home garden, CRC Press, 2 ed. Available in: https://books.google.com.br/books?id=eEy9ftsCqtoC.

Kader AA, Morris LL, Stevens MA, Albright-Holton M (1978) Composition and flavor quality of fresh quality of fresh market tomatoes as influenced by some postharvest handling procedures. American Society for Horticultural Science 103:6-13.

Mahajan G, Singh KG (2006) Response of greenhouse tomato to irrigation and fertigation. Agricultural water management 84(1-2):202-206.

Nascimento A dos R, Soares Júnior S, Caliari M, Fernandes PM, Rodrigues JPM, Carvalho WT de (2013) Qualidade de tomates de mesa cultivados em sistema orgânico e convencional no estado de Goiás. Horticultura Brasileira 31(4):628-635. DOI: http://dx.doi.org/10.1590/S0102-05362013000400020

Ochoa-Velasco CE, Valadez-Blanco R, Salas-Coronado R, Sustaita-Rivera F, Hernández-Carlos B, García-Ortega S, Santos-Sánchez NF (2016) Effect of nitrogen fertilization and Bacillus licheniformis biofertilizer addition on the antioxidants compounds and antioxidant activity of greenhouse cultivated tomato fruits (Solanum lycopersicum L. var. Sheva). Scientia Horticulturae 201:338-345. DOI: http://dx.doi.org/10.1016/j.scienta.2016.02.015

Padilla FM, Peña-Fleitas MT, Gallardo M, Thompson RB (2015) Threshold values of canopy reflectance indices and chlorophyll meter readings for optimal nitrogen nutrition of tomato. Annals of Applied Biology 166(2):271-285. DOI: http://dx.doi.org/10.1111/aab.12181

Parisi M, Giordano L, Pentangelo A, D'Onofrio B, Villari $G$ (2006) Effects of different levels of nitrogen fertilization on yield and fruit quality in processing tomato. Acta Horticulturae (700):129-132. DOI: http://dx.doi.org/10.17660/ActaHortic.2006.700.19

Peng S, Cassman KG (1998) Upper Threshholds of Nitrogen Uptake Rates and Associated Nitrogen Fertilizer Efficiencies in Irrigated Rice. Agronomy Journal 90(2):178. DOI:

http://dx.doi.org/10.2134/agronj1998.00021962009000020 010x

Qian W, Hong S, Minzan L, Wei Y (2014) Development and application of crop monitoring system for detecting chlorophyll content of tomato seedlings. International Journal of Agricultural \& Biological Engineering 7(2):138-145. DOI: http://dx.doi.org/10.3965/j.ijabe.20140702.017

Radzevičius A, Viškelis P, Viškelis J, Karklelienė R, Juškevičienė D (2014) Tomato fruit color changes during ripening on vine. International Journal of Biological, Biomolecular, Agricultural, Food and Biotechnological Engineering 8(2):112-114.

Ribeiro AC, Guimarães PTG, Alvarez VVH (eds.) (1999) Recomendações para o uso de corretivos e fertilizantes em Minas Gerais - $5^{\circ}$ aproximação. Viçosa, Universidade Federal de Viçosa, 359p. Available in: http://www.labominas.com.br/userfilesfiles/5aproximacao.pdf.

Schmidt D, Zamban DT, Prochnow D, Caron BO, Souza VQ, Paula GM, Cocco CC (2017) Caracterização fenológica, filocrono e requerimento térmico de tomateiro italiano em dois ciclos de cultivo. Horticultura Brasileira 35(1):89-96. DOI: http://dx.doi.org/10.1590/s0102053620170114

Thorp KR, Wang G, Bronson KF, M Badaruddin, Mon J (2017) Hyperspectral data mining to identify relevant canopy spectral features for estimating durum wheat growth, nitrogen status, and grain yield. DOI: http://dx.doi.org/10.1016/j.compag.2017.02.024

Tremblay N, Fallon E, Ziadi N (2011) Sensing of crop nitrogen status: Opportunities, tools, limitations, and supporting information requirements. HortTechnology 21(3):274-281.

Warner J, Zhang TQ, Hao X (2004) Effects of nitrogen fertilization on fruit yield and quality of processing tomatoes. Canadian Journal of Plant Science 84:865-871. Available in: http://www.nrcresearchpress.com/doi/pdfplus/10.4141/P03 -099. Accessed: Mar 26, 2018). 